
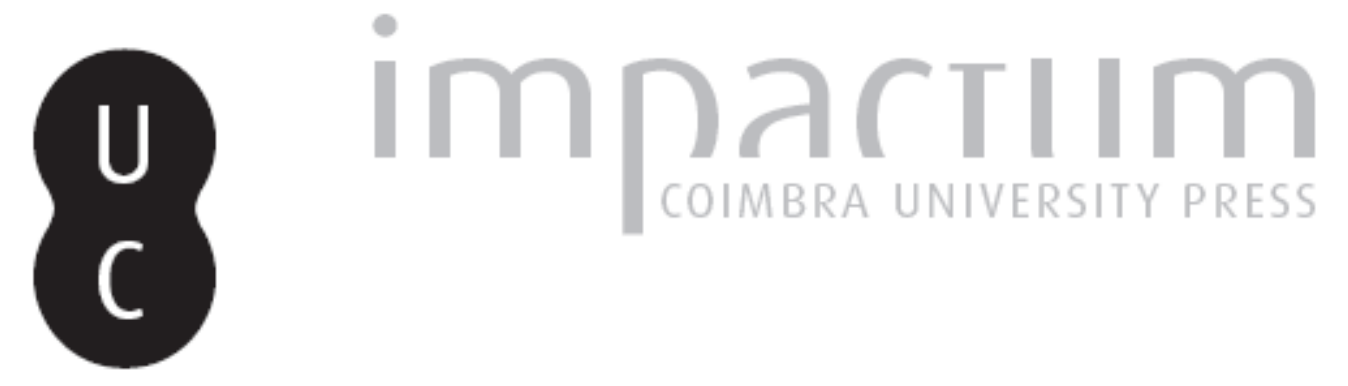

\title{
As novas odisseias de Ulisses: políticas de saúde e a imigração em Espanha e na U.E.
}

\author{
Autor(es): $\quad$ Ferreira, J. Flávio
}

Publicado por: CIAS - Centro de Investigação em Antropologia e Saúde

URL persistente:

URI:http://hdl.handle.net/10316.2/29600

DOI:

DOI:http://dx.doi.org/10.14195/2182-7982_29_11

Accessed : $\quad$ 26-Apr-2023 12:03:44

A navegação consulta e descarregamento dos títulos inseridos nas Bibliotecas Digitais UC Digitalis, UC Pombalina e UC Impactum, pressupõem a aceitação plena e sem reservas dos Termos e Condições de Uso destas Bibliotecas Digitais, disponíveis em https://digitalis.uc.pt/pt-pt/termos.

Conforme exposto nos referidos Termos e Condições de Uso, o descarregamento de títulos de acesso restrito requer uma licença válida de autorização devendo o utilizador aceder ao(s) documento(s) a partir de um endereço de IP da instituição detentora da supramencionada licença.

Ao utilizador é apenas permitido o descarregamento para uso pessoal, pelo que o emprego do(s) título(s) descarregado(s) para outro fim, designadamente comercial, carece de autorização do respetivo autor ou editor da obra.

Na medida em que todas as obras da UC Digitalis se encontram protegidas pelo Código do Direito de Autor e Direitos Conexos e demais legislação aplicável, toda a cópia, parcial ou total, deste documento, nos casos em que é legalmente admitida, deverá conter ou fazer-se acompanhar por este aviso.

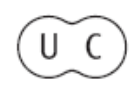




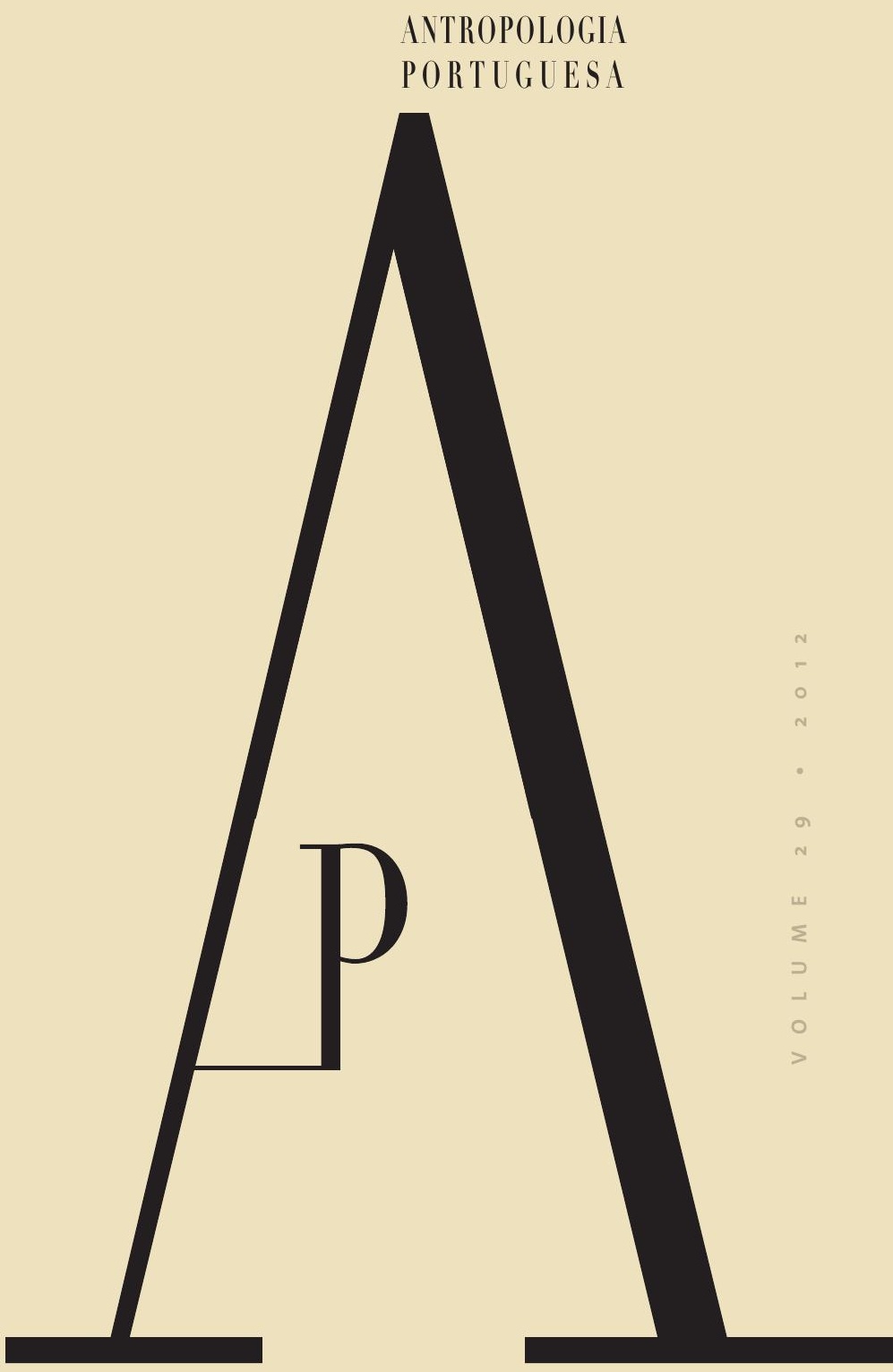

CENTRO DE

INVESTIGAÇ̃̃O

EI ANTROPOLOGIA

E SAÚDE

UNIVERSIDADE

DE COIMBRA 


\section{As novas odisseias de Ulisses: políticas de saúde e a imigração em Espanha e na U.E.}

\section{J. Flávio Ferreira*}

j.flavio.ferrer@gmail.com

Resumo Vários são os fenómenos aparentemente isolados que vêm apontar uma relação entre as políticas punitivas e/ou de controlo populacional dos Estados e a "criminalização" de determinados grupos sociais. No entanto, se tomarmos como referência a própria crise vivenciada pela União Europeia, é possível perceber-se uma ambiguidade em relação à imigração "extracomunitária" na Europa contemporânea que ora intercambia o discurso punitivo com um discurso de "integração" baseado em políticas multiculturais. A síndrome de Ulisses, modelo psiquiátrico cada vez mais popular nos Estados da U.E. para explicar a sintomatologia específica de imigrantes não-europeus, vem evidenciar as contradições desta relação. Tanto no campo da "saúde", quanto da política carcerária, a U.E.
Abstract There are several phenomena that although seemingly isolated, point out to a relationship between State's punitive and/or population control policies and the criminalization of specific social groups. However, if we take as reference the very crisis experienced by the European Union, it is possible to perceive an ambiguity with respect to non-European immigration in contemporary Europe, that interchanges the punitive discourse with an "integration" discourse based on multicultural policies. The Ulysses syndrome, a psychiatric model increasingly popular in the EU States, explains the specific symptoms of non-European immigrants and highlights the contradictions in that relationship. Both in the field of "health", as to in the prison policy, the EU

* Centro de Estudos Sociais(CES), Faculdade de Economia, Universidade de Coimbra, Portugal 
prolonga-se potencialmente como um laboratório do "olhar colonial", no qual o imigrante extracomunitário - principalmente o "ilegal" vem sendo crescentemente compreendido como um ser que se contrapõe à noção de "modernidade". A partir da correlação Estado/ política de controlo de fronteiras pretende-se aqui revisitar este complexo contexto em perspectiva pós-colonial crítica.

Palavras-chave Psiquiatria; imigração; síndrome de Ulisses; controlo social.

La geografia tradicional roba el espacio, como la economia imperial roba la riqueza, la historia oficial roba la memoria y la cultura formal roba la palabra.

"El mapa miente" - Eduardo Galeano

\section{Maresias}

A partir de meados de 1900, um considerável número de navios que partiam de diversas localidades para a Inglaterra foi enviado de volta. Oficialmente, o controlo sanitário inglês alegava ter encontrado a bordo "riscos para a saúde pública", cumprindo assim o seu papel protecionista para com a população nacional.

Os tripulantes - uma vez detectado o risco - eram recusados pelos serviços de extends potentially as a laboratory of the "colonial gaze" in which the non-European immigrant, especially the "illegal", is increasingly being understood as a person that opposes the notion of "modernity". Based on the correlation between State/border control policy, this paper aims to review this complex context from a post-colonial critical perspective.

Key words Psychiatry; immigration; Ulysses syndrome; social control.

fronteira ingleses e, portanto, obrigados a retornarem ao ponto de partida ou a tentarem outros portos que os aceitassem. Das muitas embarcações rejeitadas, grande parte era tripulada por imigrantes leste-europeus, sobretudo judeus, e por irlandeses.

As diretrizes legais apoiavam-se na Aliens Act', de 1905, que vinha a dar respostas no campo político-legal aos sentimentos sociais derivados dos fluxos imigratórios das duas décadas anteriores compostos, sobretudo, de polacos e russos judeus - os quais viriam a produzir forte sentimento de xenofobia transversal a quase toda a sociedade inglesa (Reinecke, 2009: 44-45).

\footnotetext{
1 Conhecida como An Act to amend the law with regard to Aliens, promulgada pelo Parlamento do "Reino Unido da Grã-Bretanha e Irlanda".
} 
As inspeções das autoridades sanitárias visavam, em geral, encontrar algum enfermo nas aduanas portuárias e nas embarcações para, então, imbuídos de suficiente legitimidade e do sentido de defender a pátria, recusar toda a tripulação. A aversão social aos polacos e russos judeus enraizava-se nas influências do antissemitismo em voga à época pela contínua chegada de mais imigrantes, enquanto a aversão aos irlandeses vinha de um sentido popular representativo do seu desejo de exclusão: a sociedade inglesa via nestes últimos um bando de «ladrões e pessoas intelectualmente lentas...» (Gordon, 1983), as quais poderiam deixar as suas "baixas qualidades" impregnadas na sociedade ao misturarem-se com os "locais".

Os sentimentos sociais anti-imigração foram fortemente abraçados pela Aliens Act. Antes de 1905, o governo inglês somente podia deportar os imigrantes irlandeses, e nada podia fazer com relação aos de outras nacionalidades - um problema derivado da ausência de aparatos jurídicos na relação entre o Estado e as suas populações.

De toda a forma, o discurso da "saúde pública" que impulsionava uma tecnologia do controlo populacional veio a acalmar a grande parte dos cidadãos ingleses que comungava do sentimento xenofóbico então sedimentado; tanto quanto oferecia mecanismos ao governo para se livrar de grandes contingentes de imigrantes indesejáveis (Reinecke, 2009).
O imaginário popular dos imigrantes como pessoas "sujas", "doentes" e predominantemente "pobres", sem condições mínimas de vida segundo os padrões ingleses que emergiam com a industrialização, acabava por oferecer "soluções" rápidas a problemas socioeconómicos e políticos: a recusa dos novos imigrantes e a deportação dos que já estavam no país ajudavam a "limpar" as ruas e a sociedade em geral, e diminuíam a possibilidade de propagação de "doenças". Assim, a política do governo britânico começava por excluir imigrantes pobres, que eram considerados um «fardo» para o mercado de trabalho e para a sociedade inglesa. Depois de 1905, com a Aliens Act, como aponta Reinecke:

arriving migrants were interrogated by immigration officers at the ports. They had to prove that they could support themselves as well as their "dependants", which usually meant their wives and children. If not, they were denied access to the country. Immigrants could also be refused permission to land on medical grounds. When they were judged to be either an actual threat to public health, or to be of a physical condition that hindered them from earning their own living, they were sent back (2009: 45).

As "políticas de saúde", àquela altura, projetavam no imigrante um "perigo sanitário", que de facto sublinhava nada 
mais do que uma peniafobia social e um desejo sociopolítico "anti-imigrante", como nos deixa perceber a autora. Nas vistorias portuárias, somente os imigrantes com bilhetes de cabines (consideravelmente mais caros do que os das acomodações coletivas) podiam passar livremente pelas aduanas.

Este contexto do início de 1900 que enquadra o imigrante pobre como "perigoso", potencialmente "doente" e, também por isto, indesejado, pode-nos parecer distante, mas não de todo invulgar...

É em meados de 2005, por volta de 100 anos após a Aliens Act britânica, que nos media internacionais ecoam as chegadas de inúmeras embarcações de pequeno porte repletas de imigrantes "ilegais" (africanos, sobretudo) das costas norte e oeste africanas para a costa peninsular espanhola. As pateras ou cayucos, como ficaram conhecidas as embarcações de pequeno porte e sem condições, repletas de "ilegais", foram alvo (e continuam sendo) de grande policiamento para a "proteção" das fronteiras².

Calcula-se que em 2006, ano que marcou o recorde deste fenómeno, tenha chegado a 31.678 o número de "ilegais" que arriscaram a travessia entre as

2 Para uma análise brilhante sobre a condição do imigrante na sociedade de acolhimento (ou na que este tenta "entrar"), bem como a força do imaginário que se produz sobre este e a sua consequente marginalização social e política, ver Bastos (2009).
Ilhas Canárias e a costa da península³. No total, neste mesmo ano, o número de "imigrantes ilegais" chegou a 48.180, somente em Espanha (Migreurop [Informe], 2010: 21).

Estes números são projeções, uma vez que, como é sabido e sistematicamente reforçado pelas autoridades espanholas, há uma percentagem considerável de pessoas que "não terminam" a travessia. Em Julho de 2008, o jornal português Público referiu-se aos dados noticiados por uma rádio espanhola acerca de mais uma embarcação que chegava à costa:

A rádio indicou que uma patrulha da polícia marítima interceptou um barco durante a noite, ao largo da província de Almeria (sul de Espanha), com 35 sobreviventes a bordo, incluindo três mulheres grávidas. Os sobreviventes indicaram que 14 pessoas morreram durante o percurso, incluindo nove crianças com idades compreendidas entre os 12 e os 4 anos... De acordo com a agência Europa Press, uma outra pessoa morreu igualmente antes de chegar a terra, tendo o $15 .^{\circ} \mathrm{ca}$ dáver sido encontrado a bordo da embarcação, na altura do resgate. A polícia

\footnotetext{
3 Jornal El Día "Frontex reduce los agentes que vigilan la costa africana y la salida de cayucos", de 01-02-2011. Disponível em: http://www.eldia. es/2011-02-01/canarias/2-Frontex-reduce-agentes-vigilan-costa-africana-salida-cayucos.htm; Acedido pela última vez em 05-04-2011, às 18h15; Frontex (Agencia Europea de Fronteras Exteriores).
} 
está a interrogar os sobreviventes a fim de determinar o que é que aconteceu aos cadáveres das outras 14 pessoas, mas a explicação mais plausivel é que os seus corpos tenham sido arremessados borda fora... ${ }^{4}$

Os dados oficiais disponíveis apontam para uma redução deste fenómeno de "ilegais", que caiu consideravelmente para a marca dos 19.728 imigrantes que tentaram, em 2009, atravessar para a Espanha sem permissão (Migreurop Informe, 2010: 21). Esta queda deve-se sensivelmente a dois fatores principais: (I) aumento do policiamento de fronteira, o que desencorajou a tentativa de muitos, e o (II) estabelecimento de acordos internacionais de policiamento com países africanos, como forma de assegurar que muitas das travessias das pateras fossem fracassadas já em seus locais de partida o que resulta não necessariamente numa baixa dos desejos de imigrar destas populações, oriundas, sobretudo, de África, mas antes numa baixa na contabilidade da polícia marítima espanhola.

Após reiteração do então Presidente José Luis Zapatero, em diversas reuniões de Estado, de que este tema deveria ser

\footnotetext{
4 Jornal Público "Imigração ilegal: 14 pessoas morreram em barco antes de chegarem a Espanha", de 10-07-2008. Disponível em: http://www. publico.pt/Sociedade/imigracao-ilegal-14-pessoas-morreram-em-barco-antes-de-chegarem-a-espanha_1335026]; acedido pela última vez em 05-04-2011, às $13 \mathrm{~h} 28$.
}

tratado «preventivamente como uma questão comunitária», a União Europeia resolveu por bem destinar à Espanha, entre 2009 e 2010, uma ajuda de cerca de 90 milhões de euros destinada exclusivamente ao controlo fronteiriço da "imigração ilegal". Este valor representa por volta de $20 \%$ do orçamento comunitário total para esta finalidade.

Tal política veio a cargo do chamado Plan África, um tratado de cooperação entre o Estado espanhol e países africanos considerados focos de saída de mais "aventureiros" sem visa. Em troca, os países africanos aliados à política de vigilância logram acesso a um fundo da Agencia Española de Cooperación Internacional para el Desarrollo (Aecid) de 10 milhões de euros, destinado ao fortalecimento das suas instituições públicas (Migreurop Informe, 2010: 23).

De toda a forma, é bem verdade que o contexto britânico de 1900 difere da atualidade espanhola [e da U.E. como um todo], mas os pontos fundamentais que ressaltam possíveis equivalências históricas na forma de tratamento e "criminalização" do imigrante são latentes. Além da alusão ao marítimo como palco de ambos os processos, britânico e espanhol, o discurso que os aproxima - e ao mesmo tempo os diferencia de outros - é a junção de perspectivas da "periculosidade" e da "saúde" como forma a isolar os "indesejados". 
O processo de globalização hegemónico (Santos, 2002; Santos e Avritzer, 2002) vem trazendo uma série de desafios para se compreender os limites do Estado gerados pelo modelo económico único global. Não se trata aqui, nos limites desse trabalho, de analisar as transformações que a instituição "Estado" sofreu (e vem sofrendo) e as múltiplas questões inerentes a estes processos. Trata-se de apontar como as políticas contemporâneas de combate à "imigração ilegal" na U.E. estão voltadas à aplicação de políticas punitivas à pobreza.

De facto, há uma linearidade entre as duras condições de vida dos imigrantes ilegais e aspectos relacionados à pobreza e/ou à sua falta de infraestruturas, que acabam por sedimentar uma relação entre a exclusão e a criminalização dos imigrantes. Um trabalho esclarecedor nesse aspecto foi realizado por Marta Masó (2008), no qual se percebe um processo de etiquetação do imigrante - enquanto fenómeno recorrente na Europa nas últimas décadas -, dando origem a uma tendência jurídica/prisional diferenciada desse grupo social. Em alguns países europeus os imigrantes presos alcançam um percentual de quase $50 \%$ da população carcerária total ${ }^{5}$.

No caso espanhol, o enquadramento do imigrante segundo questões discur-

\footnotetext{
5 Para mais detalhes, ver Masó (2008). Outro trabaIho que caminha na mesma direção foi desenvolvido por Roberto Bergalli (2006).
}

sivamente ligadas à "saúde" vêm reforçar esta perspectiva. É no contexto espanhol que emerge recentemente um novo aparato tecno-psiquiátrico para designar o mal-estar dos imigrantes (incidindo em maior peso, como veremos e por questões conceituais, sobre os "ilegais"), conduzindo-os potencialmente ao estatuto de "doentes". Um novo quadro clínico é proposto à comunidade médico-psiquiátrica para tratar exclusivamente os imigrantes: a Síndrome de Ulises, ou Síndrome del inmigrante con estrés crónico y múltiple (Achotegui, 2002, 2004) ${ }^{6}$.

Joseba Achotegui, psiquiatra e professor da Universidade de Barcelona, também diretor do SAPPIR ${ }^{7}$, defende a utilização de seu quadro de análise para explicar os sintomas do foro psicológico que assolam, exclusivamente, os "imi-

6 Discussões acerca da Síndrome de Ulisses podem ser encontradas na bibliografia disponível em Portugal, ainda que esta tenha sido trabalhada de forma pouco ampla, ou seja, cujos focos de análise incidem sobretudo na relação terapêutica do imigrante considerado doente em clínicas e centros de tratamento psiquiátrico transcultural ou etnopsiquiátrico. Para uma rica análise neste sentido, ver Lechner (2007: 84-86). Embora esta seja uma perspectiva essencial para se compreender o fenómeno da Síndrome de Ulisses, o enquadramento da produção do saber na psiquiatria e as conjunturas macropolíticas que implicam no rebaixamento dos imigrantes nos grandes blocos económicos - sobretudo dos imigrantes ilegais - deve ser problematizada segundo aspectos globais.

Servicio de Atención Psicopatológica y Psicosocial a Inmigrantes y Refugiados. 
grantes" do século XXI. Descoberta em meados de 2002, desde a agudização da crise de "ilegais" que utilizavam as pateras, por volta de 2005, esta síndrome vem sendo crescentemente utilizada nos casos clínicos de imigrantes por toda a U.E. (Cuestas, 2011: 25). Achotegui recorre ao mito de Ulisses como alusão às dificuldades encontradas por estes nas suas "odisseias pessoais":

Malos tiempos aquellos en que la gente corriente ha de comportarse como héroes para sobrevivir. Ulises era un Semidios, que sin embargo, a duras penas sobrevivió a las terribles adversidades y peligros a los que se vio sometido, pero las gentes que llegan hoy a nuestras fronteras tan solo son personas de carne y hueso que sin embargo viven episodios tan o más dramáticos que los descritos en la Odisea (Achotegui, 2004: 39).

A Síndrome de Ulisses respeita que há no percurso migratório un desequilibrio sustancial entre las demandas ambientales percibidas y las capacidades de respuesta del sujeto (Achotegui, 2008: 2). A Odisseia, metáfora à condição de vida do "imigrante" - presente, sobretudo, na instabilidade económica e na marginalização que assola os "ilegais" -, pressupõe a vivência de dois fatores negativos essenciais: o estrés e o duelo, este último definido pelo psiquiatra como el proceso de reorganización de la personalidad que tiene lugar cuando se pierde algo significativo para el sujeto.

Desta base experimentacional, a síndrome possui como dispositivos 7 duelos representacionais das dificuldades dos imigrantes, ou elementos estresores: 1. Ia familia; 2 . los seres queridos; 3. la lengua; 4. la cultura; 5. la tierra; 6. el estatus social; 7. el contacto con el grupo de pertenencia; os quais somados resultam em potenciais riscos à integridade psíquica e/ou física do indivíduo. Os sintomas descritos por Achotegui, cujo conjunto compõe uma síndrome, seriam diferenciados nos imigrantes justamente pelas dificuldades somadas de todos os elementos causadores de stresse acima indicados: as perdas dos laços familiares e das redes sociais, as dificuldades nos contrastes culturais e as condições laborais precárias no país de acolhimento.

Para aquele que não conseguisse ser forte o suficiente para ultrapassar as ditas dificuldades, o enquadramento clínico de acordo com a Síndrome de Ulisses viria a indicar o surgimento na área da "ansiedade" de: "tensões", "nervosismo", "preocupações excessivas e recorrentes", "irritabilidade", "insónia", dentre outros; assim como sintomas somatomorfos como "cefaleia" e "fadiga"; e ainda sintomas na área confusional como "falhas de memórias" e a forte sensação de "sentir-se perdido" (Achotegui, 2008: 10-11). 


\section{Rebordos}

Achotegui está correto ao alegar que os episódios próprios de um percurso migratório podem ser "dramáticos", so-

bretudo se os indivíduos em questão são socialmente indesejáveis e, mais ainda, se o corpo estatal do país de acolhimento possui mecanismos jurídicos para designá-los como "ilegais"; justificando, assim, as suas deportações. Não estariam, no entanto, todos os imigrantes condenados ao desenvolvimento da Síndrome de Ulisses, mas é certo, segundo o psiquiatra espanhol, que os sin papeles e aqueles que encontram nas suas trajetórias as condições mais duras seriam justamente os candidatos ao adoecimento.

Há aqui, a meu ver, algum problema de "tradução". Se a Sindrome del inmigrante con estrés crónico y múltiple é o «mal do imigrante no século XX|», sugerindo que o quadro clínico proposto por Achotegui se insere numa "leitura política" da atualidade, seu enquadramento dos fenómenos derivados dos crescentes fluxos de pessoas inerentes à globalização não respeita, todavia, uma "perspectiva politizada" dos nossos tempos. Há uma diferença entre uma leitura dos processos inerentes à globalização que abriga as ideologias sociopolíticas que constituem os nossos modelos epistemológicos, e uma tradução destes mesmos processos com referências críticas à realidade.
Entre o final do século XIX e início do século $X X$, o médico alemão Emil Kraepelin, considerado o pai da psiquiatria científica moderna, defendeu que as enfermidades psiquiátricas seriam causadas, principalmente, por desordens biológicas e genéticas. De facto, as suas teorias permitiram avanços no campo da ciência, e são agora espelhadas nas aplicabilidades das descobertas mais recentes, como o projeto genoma. No entanto, as duplicidades metodológicas introduzidas por Kraepelin nas ciências com vista a isolar as origens dos problemas da saúde, no campo da psiquiatria e não só, enraizaram também uma perspectiva demasiada essencialista da ligação entre doença e biologia. Ele acreditava, por exemplo, que as síndromes psiquiátricas (conjunto de variações sintomáticas associadas a uma patologia) observadas em «diferentes culturas» teriam uma raiz comum, por mais que a expressão fenomenológica diferisse uma da outra. O que significa, portanto, dizer que há diferentes propensões dentre "diferentes grupos humanos" no desenvolvimento de doenças universais, tendo como fator-base destas "tendências" as suas qualidades biológicas/genéticas.

Não podemos esquecer que à altura de Kraepelin o conceito de raça estava intimamente ligado às pesquisas científicas. De toda a forma, os recursos técnicos da época não permitiam muitas vezes comprovar empiricamente as 
descobertas científicas. Kraepelin propunha explicações biológicas/genéticas às causas da enfermidade mental, porém os recursos de construção das suas teorias baseavam-se mais em observações comportamentais de um indivíduo do que na patologia clínica, estritamente ${ }^{8}$.

Ora, uma vez que as origens biológicas de uma doença são explicadas em grande peso pelos comportamentos individuais e/ou de grupo, e cuja marca da época - por limites técnicos e processos político-históricos específicos - é a distinção de pessoas pelo fenótipo (sinal essencial das raças à altura), podemos supor ser este um exemplo das ideologias que compõem o saber científico: a separação de "grupos humanos" ideais estava vinculada necessariamente aos termos nosológicos das doenças específicas a que cada qual seria mais propenso a desenvolver ${ }^{9}$.

8 Para uma análise aprofundada das problemáticas da nosologia psiquiátrica desde Kraepelin aos dias de hoje, ver Duero e Shapoff (2009).

9 A psiquiatria é uma área do conhecimento que serve bem à tentativa de demonstrar o choque entre a perspectiva da "universalidade" das doenças e outras formas psico-cognitivas específicas ao redor do globo. Este foi o papel assumido pela chamada psiquiatria transcultural, difundida fortemente a partir da década de 1980. De toda a forma, após mais de 100 anos das teorias de Kraepelin, a psiquiatria moderna continua a basear-se mais na observação comportamental e isolamento sintomatológico baixo um sistema patogénico ainda demasiado teórico. A perspectiva de que o conhecimento científico é fruto de um contexto político, histórico, económico e social, em termos
Uma vez que a teoria patogénica para Kraepelin é direcionada à biologia e que, por contraste, as suas experiências basearam-se quase que estritamente na análise comportamental - sendo que o fenótipo se sobrepunha à raça e o comportamento à cultura - pode-se refletir se a patologia não seria também uma sobreposição da cura à cultura.

A Síndrome de Ulisses e a sua aplicação elucidativa do mal-estar psicológico originária nos fluxos imigratórios de "ilegais", no século XXI, vem demonstrar como as metodologias de Kraepelin continuam tão atuais na psiquiatria. Parte-se do pressuposto de que há uma descoberta patológica obedecendo, todavia, um modelo de patogénese e patoplasticidade médica universalista. $O$ próximo passo seria provar quais são os desígnios biológicos que sustentam tal argumentação.

Há aqui implicitamente uma abordagem que, não podendo ser comprovada pela patologia clínica, remonta às condições kraepelinianas de pura observação comportamental, onde os elementos que potencializam o mal-estar do "imigrante" (principalmente quanto

epistemológicos, implica tanto na necessidade de se rever as influências contextuais recebidas pelas "teorias clássicas", como as de Kraepelin, como também os impactos e incongruências das suas aplicabilidades nos dias de hoje. Para complexificações mais aprofundadas sobre a construção do saber biomédico empregue na psiquiatria e as suas problemáticas face à diversidade cultural e "étnica" dos pacientes ver, por exemplo: Littlewood e Lipsedge (1982); Fernando (2002). 
aos "ilegais") são as emoções negativas derivadas do seu "fracasso" migratório, ou, por outras palavras, do seu "fracasso" económico:

Soledad, miedo, desesperanza, ..las migraciones del nuevo milenio que comienza nos recuerdan cada vez más los viejos textos de Homero "...y Ulises pasábase los días sentado en las rocas, a la orilla del mar, consumiéndose a fuerza de llanto, suspiros y penas, fijando sus ojos en el mar estéril, Ilorando incansablemente... (Odisea, Canto V), ó el pasaje en el que Ulises para protegerse del perseguidor Polifemo le dice "preguntas cíclope cómo me llamo...voy a decírtelo. Mi nombre es Nadie y Nadie me llaman todos..." (Achotegui, 2008: 3).

A costa peninsular espanhola é, potencialmente, um "laboratório" que vê na diferença do outro a anti-marca da modernidade, enquanto a Síndrome de Ulisses tenta provar à ciência que os sintomas derivados de problemáticas sociopolíticas são representativos de uma nova descoberta. Na Síndrome de Ulisses o indivíduo é considerado a partir de três tipos de experiências migratórias, cada qual com diferentes graus de dificuldades e risco de se obter a desordem:

1- El duelo simples - es aquel que se da en buenas condiciones: (...) cuando emigra un adulto joven que no deja atrás ni hijos pequeños, ni padres enfermos, y puede visitar a los familiares; 2- El duelo complicado: (...) aquele en el que se emigra dejando atrás hijos pequeños y padres enfermos, pero es posible regresar, traerlos...; 3- El duelo extremo: es tan problemático que (...) supera las capacidades de adaptación del sujeto (este sería el duelo próprio del Síndrome de Ulises): cuando se emigra dejando atrás la familia, especialmente cuando quedan en el país de origen hijos pequeños y padres enfermos, pero no hay posibilidad de traerlos ni de regresar con ellos, ni de ayudarles (Achotegui, 2005: 2).

Neste caso, o acesso às condições materiais é preponderante para o afastamento ou proximidade do risco de se "estar doente". O enquadramento do "doente" segundo critérios "culturais", "étnicos" ou "económicos" pode ser bastante problemático. Santiago-Irizarry (2001), por exemplo, descreve-nos os programas psiquiátricos para "latinos" nos EUA (na sua maior parte mexicanos) que acabam por conduzir à produção de estigma social e políticas de assimilação cultural no país de acolhimento através das instituições psiquiátricas modernas - o que provoca ao imigrante um legado de inferiorização no imaginário social.

Se ao analisar o imigrante a Síndrome de Ulisses não escapa a uma leitura estritamente comportamental, que pelas con- 
dições materiais inscrevem em seu corpo as margens da doença, não estaria a nossa ciência a considerar a cultura e a pobreza como patologias? Não estaria a psiquiatria a ser também, em nossos tempos, marcada por ideologias da intolerância?

\section{À deriva - conclusões finais}

Se os judeus polacos e russos não eram bem quistos na Inglaterra em 1900, uma vez que «tiravam o trabalho» aos ingleses e marcavam a cidade pela «sua pobreza», não sendo mais do que «pessoas insalubres» (Reinecke, 2009: 45), não se pode afirmar, ao mesmo tempo, que os "imigrantes ilegais" não ocupam semelhante espaço no imaginário europeu atual. As nomenclaturas e definições de há cem anos poderiam sobrepor perfeitamente as que aparecem nos jornais europeus e na opinião pública atualmente ${ }^{10}$.

Em tempos de "crise financeira" global, manifestações de xenofobia têm-se

\footnotetext{
10 Para uma análise detalhada acerca da xenofobia em Espanha, ver D’Ancona (2008) "Evolución del Racismo y la Xenofobia en España", a cargo do Observatorio Español del Racismo y la Xenofobia e da Dirección General de Integración de los Inmigrantes (Secretaría de Estado de Inmigración y Emigración). O estudo levado a cabo por D'Ancona demonstra um crescimento da xenofobia em Espanha nos últimos anos, com 69\% da população inquirida a alegar que o número de imigrantes no país é "excessivo", contra somente $2 \%$ a alegar que o número é "suficiente" - 26\% alegou ser "aceitável".
}

alastrado por toda a Europa: "British jobs for British workers" eram as palavras inscritas nas placas de manifestantes ingleses, em 2007"11, numa Europa que finge ignorar a sua necessidade de trabalhadores subempregados e sub-reconhecidos financeiramente para o desenvolvimento da sua economia face ao "envelhecimento populacional" que a acomete. É claro que o neoliberalismo distribui expansões e retrações nos mercados de acordo com as suas necessidades globais, e isso implica na demanda de trabalho para os chamados "imigrantes económicos"12.

11 BBC News: "What does 'British jobs' pledge mean?", de 16-11-2007. Disponível em: http:// news.bbc.co.uk/2/hi/uk_news/politics/7097837. stm; acedido pela última vez em 06-04-2011; ou "In Britain, anger against foreign workers grows", de 31-01-2009 - Digital Journal - disponível em: http:// www.digitaljournal.com/article/266249; acedido pela última vez em 06-04-2011.

12 A percepção das ambiguidades discursivas da U.E. na questão da imigração torna-se mais clara ao se ler as declarações no próprio sítio da comunidade, com relação à política a ser adotada: “Os dirigentes da U.E. estão também a desenvolver uma política de imigração da U.E. comum, equilibrada e global com vista a tirar partido das oportunidades que a imigração legal poderá representar para as economias e sociedades europeias e a resolver simultaneamente os problemas decorrentes da imigração clandestina. Pretende-se ter em conta as prioridades e necessidades de cada país da U.E. e promover a integração dos cidadãos de países terceiros nas respectivas sociedades de acolhimento. A U.E. esforça-se também por estabelecer parcerias com os países de origem e de trânsito dos imigrantes com vista a gerir melhor a imigração legal e a reduzir a imigração clandestina, a melhorar a relação entre migração e desenvolvimento, bem como a reforçar o Estado de direito e a promover o respei- 
E é claro, também, que isso pode provocar modificações na percepção popular acerca dos imigrantes e na consequente mediação dos seus conflitos: «vêm roubar os nossos trabalhos». Mas a pergunta seria: como criar uma ecologia entre os mercados - e as suas implicações socioeconómicas - e o fenómeno (i)migratório nos tempos que correm? Como a indignação pela precarização das condições de vida volta-se para o outro de uma sociedade e não contra a lógica neoliberal? ${ }^{13}$

Talvez seja deste cenário mais específico que advenham os pronunciamentos na área confusional a que Achotegui faz menção, cuja sintomatologia prevê o "sentir-se perdido" por parte do imigrante "ilegal":

La confusión podría estar ligada a con el tener que esconderse, hacerse invisibles, para no ser retenidos, repatriados (en definitiva el famoso episodio de la Odisea en que Ulises le dice a Polifemo que su nombre es Nadie). Así no es infrecuente encontrar casos de menores que han pasado por numerosos centros tutelados en los que dan un nombre diferente en cada

to pelos direitos fundamentais nesses países." Ver: http://europa.eu/pol/justice/index_pt.htm. acedido pela última vez em 07-04-2011.

13 Para uma leitura acerca dos pontos inerentes a estas perguntas ver os debates levantados por Baldwin-Edwards (2001) "Southern European Labour Markets and Immigration: a structural and functional analysis" e Harris \& Coleman (2003) "Does Britain Need More Immigrants?". lugar. ¿Cuál es el verdadero? (Achotegui, 2008: 12).

De toda a forma, o pronunciamento político dos combates aos problemas ligados à imigração e à forma como o imigrante é visto - potencialmente mais rigoroso à medida em que tais problemas são agudizados - volta a repetir na história uma variação do controlo das populações através de critérios do campo da "saúde".

Se a Síndrome de Ulisses vem sanar as ruturas no conflituoso cenário europeu da "imigração ilegal", não são claras as reais dimensões sociais e políticas consequentes da sua intervenção. O modelo psiquiátrico apoia-se seguramente nas emoções e nos transtornos dos "ilegais" nas malhas da "legalidade", mas a partir deste momento cria também perfis de integração social baseados estritamente em questões económicas - mostrando mais uma vez as perspectivas de um saber universalista também pautado em termos de "produtividade", "consumo", "acesso material", "sociabilidade", etc.

Assim, o imigrante mais saudável no quadro clínico proposto por Achotegui, o do duelo simples, é aquele que não possui filhos e pais em situação de necessidade que o obriguem ao envio de remessas de dinheiro para o exterior; que é jovem e saudável para o trabalho, com documentação regular, com poder económico para regressar ao país de origem, enfim, "integrado" e propenso ao estabelecimento 
pleno no país de acolhimento, com menores probabilidades de querer acumular economias destinadas a um regresso definitivo e, portanto, consumidor e pagador de impostos sem a necessidade de ajuda do Estado. Enquanto isso, o imigrante que se enquadra no duelo extremo tem a vida transcrita num facto consumado.

Entre estes dois não-sujeitos, o do duelo simples e do duelo extremo, o saudável desde o ponto de vista europeu é justamente aquele que mais se assemelha ao nós, enquanto o doente é aquele que fica do lado de lá, com o eles. Estruturas universais baseadas em estereótipos culturais, identitários e económicos, padronizadas pelos manuais internacionais de psicopatologia, acabam, no limite, por negar o direito à subjetividade do paciente e do movimento dinâmico do seu auto reconhecimento.

Mais do que afirmar modelos, a psiquiatria destinada a imigrantes deveria ser problematizada segundo os resultados contraditórios que pode produzir nos meios social e político. Quando a mediação clínica dissocia contextos sociais, políticos, históricos e económicos os resultados são imprevisíveis, e o que se pode esperar certamente é a naturalização de mais essencialismos ${ }^{14}$.

\footnotetext{
14 Estas questões em específico foram anteriormente por mim trabalhadas numa análise sobre um grupo de psiquiatria transcultural para imigrantes em Portugal (Ferreira, 2008), com a problematização das ideologias que compõem o saber psiquiátrico e o choque do encontro deste com os saberes dos pacientes.
}

Apesar da redução no fenómeno dos "ilegais" na costa peninsular espanhola, não se pode dizer que o "problema" está resolvido. Mesmo que de forma ideal a imigração "ilegal" ganhe outros contornos: cesse ou se direcione a outro país, teremos para outros fenómenos semelhantes no futuro um referencial cravado na história. Resta perguntarmo-nos se com exemplos como a Síndrome de Ulisses estaremos a politizar a medicina ou a classificar como patológicos os problemas sociopolíticos para os quais ainda não dispomos de soluções.

\section{Referências Bibliográficas}

Achotegui, J. 2002. La depresión en los inmigrantes. Una perspectiva transcultural. Barcelona, Editorial Mayo.

Achotegui, J. 2004. Emigrar en situación extrema: el síndrome del inmigrante con estrés crónico y múltiple (Síndrome de Ulises). Revista Norte de Salud Mental, 21: 39-52.

Achotegui, J. 2005. Estrés límite y salud mental: el síndrome del inmigrante con estrés crónico y múltiple (Síndrome de Ulises). Revista Norte de Salud Mental de la Sociedad Española de Neuropsiquiatría, 5(21): 39-53.

Achotegui, J. 2008. Migración y crisis: el síndrome del inmigrante con estrés crónico y múltiple (Síndrome de Ulises). 
Advances in Relational Mental Health, 7(1): 1-22.

Baldwin-Edwards, M. 2001. Southern european labour markets and immigration: a structural and functional analysis. The
Gordon, P. 1983. Medicine, racism and immigration control. Critical Social Policy, 3(7): 6-20.

Harris, N.; Coleman, D. 2003. Does Britain Need More Immigrants? World Economics Journal, 4(2): 57-102.

Lechner, E. 2007. Imigração e saúde mental. In: Dias, S. (org.). Revista Migrações - Número Temático Imigração e Saúde, n.o 1. Lisboa, ACIDI: 79-101.

Littlewood, R; Lipsedge, M. 1997 [1982]. Aliens and alienists: ethnic minorities and psychiatry. Hove, Brunner-Routledge.

Masó, M. M. 2008. La gestión penal de la inmigración. El recurso al sistema penal para el controle de los flujos migratorios. Buenos Aires, Del Puerto.

Reinecke, C. 2009. Governing aliens in times of upheaval: immigration control and modern state practice in early twentieth-century Britain, compared with Prussia. International Review of Social History, 54(1): 39-65.

Santiago-Irizarry, V. 2001. Medicalizing ethnicity: the construction of Latino identity in a psychiatric setting. New York, Cornell University Press.

Duero, D. G.; Shapoff, V. 2009. El conflicto nosológico en psicopatología: notas críticas sobre el diagnóstico psiquiátrico. Revista CES Psicología, 2(2): 20-48.

Fernando, S. 2002. Mental health, race and culture. London, Palgrave.

Ferreira, J. F. 2008. Da imigração à patologia - biomedicina, transculturalidade e controlo. Dissertação de Mestrado em Antropologia, Departamento de Antropologia, ISCTE-Instituto Universitário de Lisboa. 


\section{Outras fontes}

FRONTEX [Agência Europeia de Fronteiras Exteriores] - http://www.frontex.europa. eu/

JORNAL EL DÍA - Frontex reduce los agentes que vigilan la costa africana y la salida de cayucos. [Online]. [Tenerife], Eldia.es - Noticias de Canarias [Acedido 05-042011]. Disponível em: http://www.eldia.es/2011-02-01/canarias/2-Frontexreduce-agentes-vigilan-costa-africanasalida-cayucos.htm.

JORNAL PÚBLICO - Imigração ilegal: 14 pessoas morreram em barco antes de chegarem a Espanha, de 10-07-2008. [Online]. [Lisboa], Público, [Acedido em 05-04-2011]. Disponível em: http://www.publico.pt/ Sociedade/imigracao-ilegal-14-pessoas-morreram-em-barco-antes-dechegarem-a-espanha-1335026].

MIGREUROP [Informe]. 2010. En las fronteras de Europa - controles, confinamientos, expulsiones. asociación pro derechos humanos de Andalucía. [Online]. [San Sebastián]. [Acedido 05-04-2011]. Disponível em: http://www.apdha.org/ media/Informe_Migreurop_2010.pdf. SAPPIR (Servicio de Atención Psicopatológica y Psicosocial a Inmigrantes y Refugiados) - http://www.fhspereclaver.org/ migra-salut-mental/ 